\title{
FORMAÇÃO PROFISSIONAL DA EDUCADORA MARIA LÍLIA IMBIRIBA SOUSA COLARES
}

\author{
PROFESSIONAL TRAINING OF EDUCATOR MARIA LÍLIA IMBIRIBA SOUSA \\ COLARES
}

\section{FORMACIÓN PROFESIONAL DE LA EDUCADORA MARIA LÍLIA IMBIRIBA SOUSA COLARES}

Lia Machado Fiuza Fialho

Universidade Estadual do Ceará - Brasil

Scarlett O'hara Costa Carvalho

Universidade Estadual do Ceará - Brasil

Francisca Mayane Benvindo dos Santos

Universidade Estadual do Ceará - Brasil

Arliene Stephanie Menezes Pereira

Instituto Federal de Educação, Ciência e Tecnologia do Ceará - Brasil

\begin{abstract}
Resumo: $\mathrm{O}$ estudo trata acerca da formação educacional, inter-relacionada à atuação docente da doutora Maria Lília Imbiriba Sousa Colares, professora de Santarém-Pará, que contribuiu efetivamente para a expansão da Pós-Graduação em Educação no oeste do Pará. O objetivo foi compreender a trajetória educativa de Lília Colares, com ênfase nas experiências formativas e profissionais que lhe possibilitaram galgar nível pós-doutoral e contribuir efetivamente com o contexto educacional de Santarém. Desenvolveu-se um estudo amparado na História Cultural, do tipo biográfico, que utilizou como metodologia a história oral de vida coletada por meio de entrevista via Google Meet com Lília Colares. As fontes orais foram analisadas no entrecruzamento com outras documentais e permitiram inferir, como principais resultados, que a biografada, mesmo diante de um contexto econômico restritivo e da instabilidade no tocante ao pingue-pongue familiar e da mudança frequente de escolas, conseguiu não apenas concluir o segundo grau, mas mudar-se para Campinas para cursar mestrado e doutorado, com o apoio do seu esposo. Essa experiência formativa possibilitou-lhe contribuir com o cenário educativo de Santarém, ao desenvolver projetos para fortalecer a gestão democrática e participar da implementação de cursos stricto sensu considerando a regionalidade e as dificuldades vivenciadas pelo povo paraense. Sua história, na trama de uma biografia de exceção, permite não apenas preservar a história e a memória de educadoras historicamente invisibilizadas, mas lançar lume aos obstáculos que impossibilitavam tantas outras mulheres de alcançar níveis mais altos de formação.
\end{abstract}

Palavras-chave: Biografia; História da Educação; Educação de mulheres.

Abstract: The study deals with educational training, interrelated with the teaching performance of Doctor Maria Lília Imbiriba Sousa Colares, a professor from Santarém-Pará, who effectively contributed to the expansion of Postgraduate Studies in Education in western Pará. The objective was to understand Lília Colares' educational trajectory, with emphasis on the formative and professional 
experiences that enabled her to reach a post-doctoral level and effectively contribute to the educational context of Santarém. A biographical study based on Cultural History was developed, which used as a methodology the oral history of life collected through interviews via Google Meet with Lília Colares. The oral sources were analyzed in the intersection with other documents and allowed to infer, as main results, that the biography, even in the face of a restrictive economic context and instability regarding family ping-pong and frequent change of schools, managed not only to conclude high school, but moving to Campinas to pursue a masters and doctoral degree, with the support of her husband. This formative experience allowed him to contribute to the educational scenario of Santarém by developing projects to strengthen democratic management and participate in the implementation of stricto sensu courses considering the region and difficulties experienced by the people of Pará. Her story, in the plot of an exceptional biography, allows not only to preserve the history and memory of educators who were historically invisible, but to cast light on the obstacles that made it impossible for so many other women to reach higher levels of education.

Keywords: Biography; History of Education; Women's education.

Resumen: El estudio trata sobre la formación educativa, interrelacionada con la actuación docente de la doctora Maria Lília Imbiriba Sousa Colares, profesora de Santarém-Pará, quien contribuyó efectivamente a la expansión de los Posgrados en Educación en el occidente de Pará. El objetivo fue comprender a Trayectoria educativa de Lília Colares, con énfasis en las experiencias formativas y profesionales que le permitieron alcanzar un nivel posdoctoral y contribuir efectivamente al contexto educativo de Santarém. Se desarrolló un estudio biográfico basado en la Historia Cultural, que utilizó como metodología la historia oral de la vida recopilada a través de entrevistas a través de Google Meet con Lília Colares. Las fuentes orales fueron analizadas en la intersección con otros documentos y permitieron inferir, como principales resultados, que la biografía, aun ante un contexto económico restrictivo e inestabilidad en cuanto al ping-pong familiar y el cambio frecuente de escuelas, logró no solo concluyó la escuela secundaria, pero se mudó a Campinas para realizar una maestría y un doctorado, con el apoyo de su esposo. Esta experiencia formativa le permitió contribuir al escenario educativo de Santarém desarrollando proyectos para fortalecer la gestión democrática y participar en la implementación de cursos stricto sensu considerando la región y las dificultades que vive la gente de Pará. Su historia, en la trama de una biografía excepcional, permite no solo preservar la historia y la memoria de educadoras históricamente invisibles, sino arrojar luz sobre los obstáculos que impidieron que tantas otras mujeres alcanzaran niveles educativos superiores.

Palabras clave: Biografía; Historia de la educación; Educación de la mujer.

\section{Introdução}

Este artigo insere-se no campo da História da Educação de mulheres educadoras e trata da biografia da professora paraense Maria Lília Imbiriba Sousa Colares, doravante apenas Lília Colares, com ênfase na sua formação educacional e atuação profissional. A trajetória de vida dessa docente universitária, bem como de outras educadoras, sejam estas anônimas, leigas ou figuras públicas, possui valor por permitir maior compreensão do seu contexto histórico, apresentando assim, características coletivas, individuais e sociais, por meio da perspectiva histórica (RODRIGUES, 2015).

A pesquisa para elaboração biográfica partiu do seguinte questionamento: Como se deu a formação educativa da professora Lília Colares para que ela pudesse atuar profissionalmente 
contribuindo para a expansão do ensino superior em nível de pós-graduação stricto sensu na cidade de Santarém no estado do Pará? Essa inquietação deu origem ao objetivo central do estudo, qual seja: compreender a trajetória educativa de Lília Colares, com ênfase nas experiências formativas e profissionais que lhe possibilitaram galgar nível pós-doutoral e contribuir efetivamente com o contexto educacional de Santarém.

A delimitação temporal do estudo foi delineada pelo ano em que Lília Colares iniciou seus estudos formais, em 1980 e o que ela concluiu seu pós-doutorado, em 2013. Já o objeto de estudo foram as narrativas biográficas de Lília Colares sobre sua formação para atuação no campo educacional.

No contexto histórico e social, ao tratar de mulheres educadoras, percebe-se que elas eram parcamente evidenciadas na História da Educação, ou seja, pouco reconhecidas na historiografia, e, até mesmo aquelas cujo seus feitos repercutiam socialmente, raramente eram consideradas figuras públicas de relevo. Portanto, é nessa esteira da concepção de que "[...] dar visibilidade à presença das mulheres na nossa sociedade nas últimas décadas é mais do que um desvelar de pequenas e, ao mesmo tempo, grandes personagens da história das mulheres no Brasil" (GODINHO, 2016, p. 15), que ensejamos luz à trajetória de vida e formação de uma mulher, santarena, educadora. Afinal, a biografia de Lília Colares é produto de individualidades imbricadas no contexto coletivo, o que permite refletir acerca dos símbolos sobre a educação do feminino e de ser mulher nortista.

Sabendo que na perspectiva tradicional da História, com cunho positivista, de caráter nacionalista, baseada em heróis e grandes feitos, não se permitia ensejar atenção à função social das mulheres enquanto protagonistas do enredo da História da Educação. No entanto, por meio das contribuições trazidas pela escola dos Annales e pela Nova História Cultural (BURKE, 2011), realizam-se diversas possibilidades de pesquisas considerando grupos específicos, a exemplo dos relacionados às mulheres educadoras. Destaca-se, inclusive, o desenvolvimento de pesquisas biográficas com educadoras já realizadas no Brasil, que originou inúmeros artigos científicos, em busca de lançar lume às mulheres que contribuíram com o cenário educativo de seu tempo, são elas: Célia Goiana (FIALHO; CARVALHO, 2017), Maria Luiza Fontenele (FIALHO; FREIRE, 2018); Henriqueta Galeno (FIALHO; SÁ, 2018); Neli Sobreira (FIALHO; QUEIROZ, 2018); Aída Balaio (FIALHO; LIMA; QUEIROZ, 2019); Argentina Pereira Gomes (MENDES; FIALHO; MACHADO, 2019); Zelma Madeira (FIALHO; HERNÁNDEZ DÍAZ, 2020); Iolanda dos Santos Gomes (MENDES, et al., 2020); Rosa Ribeiro (FIALHO; SOUSA; HERNÁNDEZ DIAZ, 2020); Raquel Dias (FIALHO; SANTOS; FREIRE, 2020); Maria Zuila Morais (LOPES; SOUSA; FIALHO, 2020); Josete Sales (FIALHO; SOUSA; NASCIMENTO, 
2020); Elisabeth Silveira (FIALHO; SOUSA, 2021), dentre outros. Na contramão do número crescente de biografia de mulheres educadoras brasileiras, quando se trata de educadoras do norte do Brasil, há relativa ausência de estudos.

Com efeito, ao contrário das biografias heroicas, esse estudo busca mostrar não somente os feitos e honras da professora Lília Colares ao longo de seu percurso educacional, mas também as dificuldades encontradas na sua trajetória de vida, pois, sem intenção de ser uma biografia exemplar, reflete uma história individual, de caráter excepcional, possibilitando lançar luz sobre os percalços que impediram tantas outras mulheres de conseguir uma formação em nível pós-doutoral no oeste do Pará. Busca-se mostrar o individual e o coletivo, que é produto da interação do momento histórico e de sua consciência, pois a História Cultural abarca artes do passado (BURKE, 2005) e traz um novo paradigma, por ser mais eclética no coletivo e no individual (LORIGA, 2011).

Na História da Educação e da Pedagogia não se pode conceber uma visão hegemônica, assim, a relevância do gênero biográfico para a História da Educação apresenta as características únicas e diversificadas da história, tanto local como geral. Como destaca Thompson (1992, p. 302), "a vida individual é o veículo concreto da experiência histórica", e comungando com esse autor, Dosse $(2015$, p. 11) assevera que a biografia é um elemento privilegiado para o estudo histórico, já que permite “[...] a reconstituição de uma época, com seus sonhos e angústias".

O artigo está organizado em seis seções, quais sejam: "Introdução", que elucida a temática, o problema e objetivo de pesquisa, o objeto de estudo, e a perspectiva biográfica adotada; "Metodologia", onde se explicita o percurso para o desenvolvimento do estudo à luz da história oral biográfica; "Formação educacional da professora Lília Colares", na qual é apresentada sua composição familiar e trajetória educativa nas escolas de Santarém; “Atuação docente e contribuições educacionais da professora Lília Colares", onde se discute as contribuições da docente no cenário educativo do Pará; e "Considerações Finais", que buscam retomar o problema de pesquisa e responder ao objetivo proposto, apontando limitações e sugestões.

\section{Metodologia}

A pesquisa foi desenvolvida segundo uma abordagem qualitativa (BOGDAN; BIKLEN, 1994; MINAYO, 2001), já que não se preocupa por quantificar ou generalizar dados, ao contrário, valoriza as nuances que perpassam a história individual. Tem o apoio teórico nas contribuições trazidas pela História Cultural (CHARTIER, 1988), que impulsionou o interesse 
por toda a atividade humana ao valorizar os sujeitos e suas particularidades (BURKE, 2011). Considera-se, nesse sentido, as singularidades e as regionalidades de Lília Colares por meio da "micro-história" (LEVI, 1992), destacando a importância de pesquisas locais, sem perder de vista o coletivo.

Nessa perspectiva, o estudo foi do tipo biográfico, considerando a vida da professora Lília Colares no imbricamento com o coletivo, com ênfase na sua formação educacional, o que permite contribuir para preservar a memória e a História da Educação do Pará. Trata-se, mais especificamente, de uma biografia de exceção (DOSSE, 2015), pois a trajetória da vida de Lília Colares destoa da maioria das outras mulheres do oeste do Pará de seu tempo, que não conseguiam formação em nível doutoral até o início do século XXI. Ademais, valoriza-se o destaque a questões regionais e locais que relacionam o todo pela parte, por meio das singularidades (CHARTIER, 1988).

Segundo Carino (1999, p. 169), o ato de biografar possui uma intencionalidade e finalidade da instrumentalidade educativa ao considerar a trajetória individual na sua interrelação indissociável com o coletivo, pois:

A biografia trata do individual, da trajetória de uma dada vida, específica, concreta. A educação, por seu turno, embora lidando com cada indivíduo, trata do coletivo: dos conhecimentos, normas, valores etc., com os quais esse ser individual irá participar da vida da sociedade, isto é, da instância coletiva.

Lília Colares, todavia, foi selecionada para ser biografada por sua atuação docente diferenciada, na perspectiva democrática e por suas contribuições no campo da formação de gestores e recursos humanos em programas de pós-graduação stricto sensu em Santarém-Pará. Sua trajetória individual possibilita compreender as dificuldades formativas de outras mulheres professoras em avançar nos estudos.

A narrativa biográfica de Ĺ́lia Colares foi desenvolvida por meio da metodologia da história oral biográfica (LOZANO, 2006; MEIHY; HOLANDA, 2007), que consiste na realização de entrevista em história oral. Destarte, a entrevista em história oral trata da " $[$...] manifestação do que se convencionou chamar de documentação oral, ou seja, suporte material derivado de linguagem verbal expressa para esse fim" (MEIHY; HOLANDA, 2007, p. 14). A fonte oral foi entrecruzada com fontes documentais - históricos escolares, legislação, documentos oficiais - para elaboração da narrativa biográfica.

No que se refere aos aspectos éticos da pesquisa, o convite para o empreendimento biográfico foi realizado de maneira informal, pela líder do Grupo de pesquisa "Práticas Educativas, Memórias e Oralidades”, a professora doutora Lia Machado Fiuza Fialho, que aventou essa possibilidade. De pronto, a educadora Lília Colares mostrou-se interessada em 
participar de um estudo biográfico como protagonista da narrativa. Em seguida, foi agendada uma reunião virtual para o dia 4 de junho de 2021, em decorrência da pandemia, com uma das pesquisadoras do referido grupo. Na ocasião, houve a explicação do objetivo da pesquisa, da forma de participação, da ausência de benefícios, da impossibilidade de assegurar anonimato e da possibilidade de desistência a qualquer momento.

Após a assinatura e o envio virtual do Termo de Consentimento Livre e Esclarecido, a entrevista, via Google Meet, foi iniciada às 9 horas da manhã, com duração de 1 hora e 15 minutos. Com o consentimento da biografada, houve o uso de vídeo e gravação digital das narrativas oralizadas. Realizou-se a passagem do oral para o escrito por meio da transcrição literal, seguida da textualização para retirada de vícios de linguagem e inclusão de expressões de emoção. O material textualizado foi devolvido para a colaboradora entrevistada, sendo as narrativas por ela validadas.

Destaca-se, todavia, que "os fatos narrados não são como as fontes documentais, que ficam dispostas à espera do pesquisador, mas são fragmentos de memória, retalhos descontínuos, decompostos, que, por meio da narrativa, ganham forma e consistência" (ESQUISANI, 2012, p. 223). Destarte, não se buscava uma verdade inquestionável ou uma interpretação única das narrativas orais, mas a formulação de uma narrativa crítica que considerou a memória seletiva e os lapsos de memória para “[...] compreender que as nuances da subjetividade da oralidade significa muito para uma boa interpretação historiográfica" (FIALHO; SANTOS; SALES, 2019, p. 17).

A pesquisa faz uso prioritário da memória relativa à educação, considerando que "lembrar não é reviver, mas refazer, reconstruir, repensar, com imagens e ideias de hoje, as experiências do passado" (BOSI, 1994, p. 55). Dessa forma, a professora entrevistada, mediante sua narrativa, apresenta suas memórias referentes à sua formação e atuação docente ressignificadas no tempo presente. Para Le Goff (1990, p. 423), “a memória é a propriedade de conservar certas informações, propriedade que se refere a um conjunto de funções psíquicas que permite ao indivíduo atualizar impressões ou informações passadas, ou reinterpretadas como passadas". Por fim, os dados colhidos foram analisados, tendo em vista o escopo desta pesquisa, que foi compreender a trajetória educativa de Lília Colares, com ênfase nas experiências formativas e profissionais que lhe possibilitaram galgar nível pós-doutoral e contribuir efetivamente com o contexto educacional de Santarém.

\section{Formação educacional da professora Lília Colares}

Lília Colares nasceu no dia 27 de dezembro de 1971 na cidade de Santarém, localizada a oeste do estado do Pará, na região Norte do Brasil. A economia de Santarém já se destacava 
nos setores agropecuário, de comércio e serviços, além do ecoturismo, inclusive, a cidade é conhecida pelas suas belezas naturais como, por exemplo, o encontro do rio Tapajós com o rio Amazonas. Atualmente, a população local de Santarém foi estimada, segundo o Instituto Brasileiro de Geografia e Estatística (IBGE, 2010), em 294.580 habitantes, sendo a terceira cidade mais populosa do estado do Pará, depois de Belém e Ananindeua. Todavia, tornou-se o principal centro cultural, urbano, comercial, financeiro e cultural do oeste do estado.

Acerca da cidade de Santarém-Pará a biografada destaca:

É uma cidade que é um polo, atualmente tem várias universidades, onde mais de vinte municípios que circundam Santarém vem estudar aqui nessa cidade. É o que chamamos região oeste do Pará. É como se Santarém fosse a capital do oeste do Pará. Tanto que queríamos dividir para Santarém ser a capital do oeste e Belém ficasse sendo a capital da outra parte do estado do Pará (Lília Colares, 04/06/2021).

No relato acima, Lília Colares destaca a importância da cidade, associando-a à capital do estado, Belém, pois Santarém é a cidade referência no oeste do estado, compondo uma região cercada por muitos municípios que dependem dela para ter acesso a inúmeros serviços, a exemplo da educação, por concentrar várias escolas e universidades. Dados do IBGE (2010) indicam que a rede educacional de Santarém conta com 457 escolas públicas municipais, 44 estaduais, 44 escolas particulares e doze instituições de ensino superior. Estas últimas ofertam cursos de graduação e pós-graduação, com destaque para a Universidade Federal do Oeste do Pará (Ufopa), principal estabelecimento de ensino superior da região.

Lília Colares deixa transparecer em sua narrativa a marca da sua regionalidade, a valorização e pertencimento local ao relatar: "Santarém é uma cidade muito poética, tem muitas praias bonitas, Santarém é muito cantada, tem muita música de Santarém, tem artistas santarenos. Então defendemos mesmo a nossa cidade e a nossa região" (Lília Colares, 04/06/2021). Assim sendo, nota-se que a constituição da identidade da biografada perpassa as características do seu contexto histórico-social, visto que "o contexto é um ponto de referência importante, um pano de fundo essencial para ajudar a entender a experiência e a vida do indivíduo" (VILAS-BOAS, 2014, p. 204).

No que se refere a sua infância e à formação familiar, Lília Colares destaca que sua educação não foi nos moldes de uma família nuclear, pois foi criada pelos avós e, inclusive, perdeu o contato com sua mãe: "Eu nasci em 1971, fui a primeira filha do meu pai e segunda filha da minha mãe e também fui a primeira neta dos meus avós. Os meus pais não se casaram, então eu fui criada com os meus avós paternos" (Lília Colares, 04/06/2021). Segundo Mainetti e Wanderbroocke (2013, p. 88), é relativamente comum que mulheres avós participem 
ativamente da vida familiar de seus descendentes, pois “[...] o futuro genético representado pela chegada de um neto, em meio às tarefas de aposentadoria, doenças e perda do cônjuge, traz à mulher uma nova importância e utilidade e os netos têm o poder de reavivar desejos, sonhos e ideais adormecidos". No entanto, mais do que isso, os avós de Lília Colares assumiram integralmente a educação da neta, de tal modo que a avó tornou-se sua mãe e seu avô, a figura paterna.

Como sua avó-mãe era dona de casa e seu avô-pai trabalhava como vendedor ambulante, a família vivia com poucos recursos financeiros, situação que somente melhorou um pouco quando seu avô conseguiu um emprego fixo de carregador na empresa Infraero, quando Lília Colares tinha por volta de dez anos. Embora os avós de Lília Colares não tivessem escolaridade ou boas condições financeiras, sua educação foi pautada pela valorização dos estudos, pois eles almejavam que a neta recebesse educação de qualidade para galgar uma vida mais confortável.

Apesar dos meus avós paternos não terem escolaridade, eles eram muito preocupados com que eu não perdesse o tempo de ir para a escola. Eles tinham muito cuidado com relação a isso. Como antigamente não tinha o cuidado com a Educação Infantil, geralmente as crianças eram alfabetizadas em casa ou em escolinhas. Então, quando eu tinha seis anos a minha avó me colocou na escolinha da professora Léo, que era uma professora que ensinava na casa dela algumas crianças e foi lá que eu me alfabetizei (Lília Colares, 04/06/2021).

De acordo com Freitas e Biccas $(2009$, p. 306) "Os pais percebiam claramente que a escolarização poderia ampliar o horizonte de possibilidades de seus filhos. Para cada pai, cada mãe, era plausível a utopia de construir para os filhos uma vida diferente da que tiveram. Nessa perspectiva, a escola era colocada como um fator de ascensão social". Dessa maneira, priorizouse a educação de Lília Colares, iniciada com professora leiga ${ }^{1}$. Entretanto, mesmo tendo permanecido na escolinha da professora Léo até os oito anos de idade, como o ensino residencial não era oficializado e regularizado, não emitiu registros e documentações que comprovassem os anos de estudos de Lília Colares como, por exemplo, o boletim escolar. Ademais, não existia a concepção de educação infantil como etapa importante para o desenvolvimento da criança, englobando o educar para além do mero cuidado e ensino das primeiras letras (ALVES; FIALHO, 2019).

Dessa maneira, Lília Colares foi matriculada, já alfabetizada, na $1^{\mathrm{a}}$ série do ensino primário, em uma escola municipal, como elucida no trecho abaixo:

\footnotetext{
${ }^{1}$ Denomina-se "professora leiga" aquela que não tem formação específica para atuar na sua área, ou seja, que não possuía formação inicial em Magistério.
} 
[...] eu fui matriculada na primeira série com oito anos de idade, isso se deu em 1980. Fui matriculada em uma escola próximo da minha casa chamada Rotary, essa era uma escola que a gente dizia antes assim, que apesar de ser pública, era uma escola que tinha bons professores e as pessoas queriam que seus filhos estudassem lá também. Lá eu estudei três anos, à medida que eu ia passando de série a professora também ia passando de série junto com os alunos, então a minha vida escolar no antigo primeiro grau, foi os três primeiros anos com a mesma professora. Tanto que até hoje eu lembro o nome dela, Sueli Bezerra Gomes (Lília Colares, 04/06/ 2021).

Conforme o histórico escolar (Imagem 1) é possível perceber que Lília Colares era uma aluna mediana durante os três anos que esteve matriculada na Escola Municipal Rotary, onde concluiu a $3^{\mathrm{a}}$ série, bem como na Escola Municipal Padre Manuel Albuquerque onde cursou a $4^{\mathrm{a}}$ série, em 1983. A mudança de instituição educativa deu-se pelo fato de que sua mãe resolveu convidar Lília Colares para que passasse a morar com ela.

Imagem 1 - Histórico Escolar de Lília Colares (1980-1983)

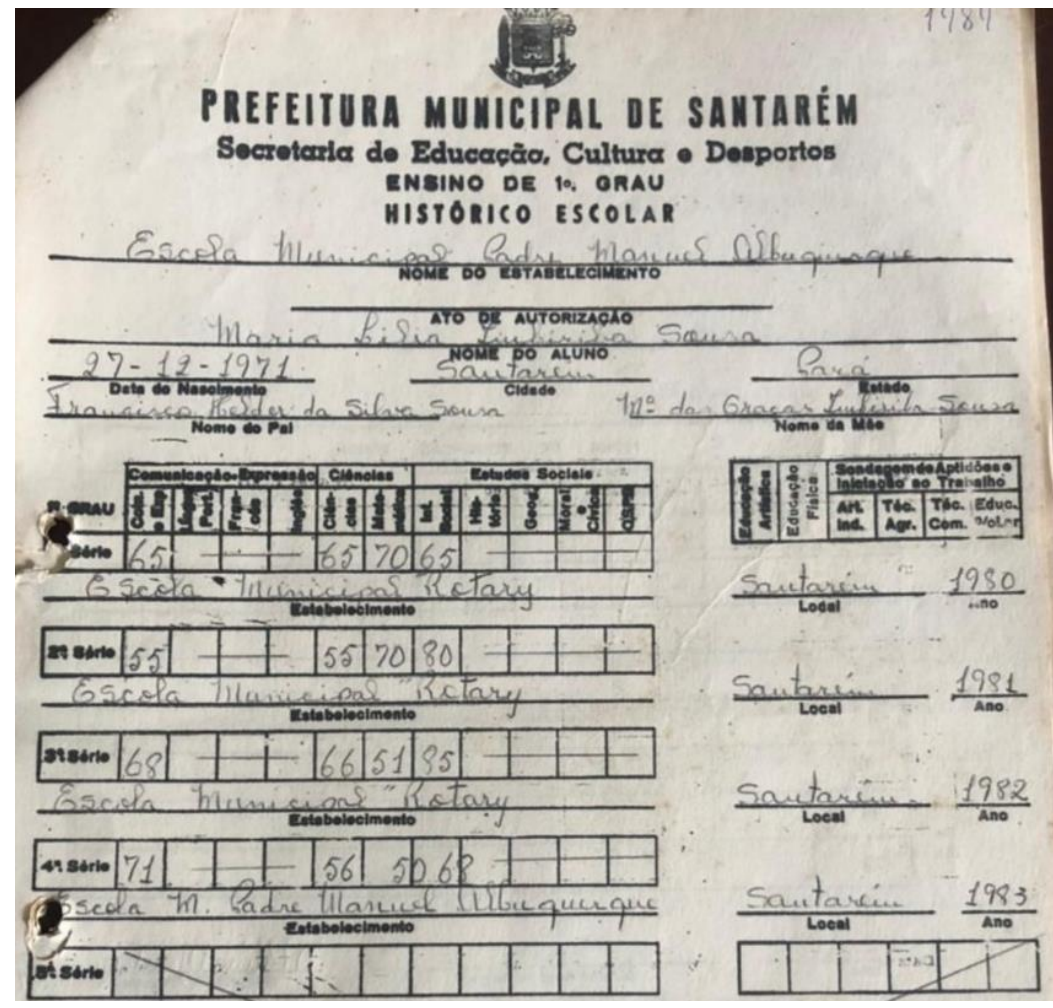

Fonte: Acervo pessoal da biografada

Sobre essa instituição, Lília Colares recorda:

Nessa escola eu só pude estudar um ano porque não tinha quinta série, depois eu fui para uma escola chamada Júlia Gonçalves Passarinho, nessa escola eu fiz a quinta série. Estudei só um ano também. E em 1986, mudei de novo de bairro e fui estudar na escola Almirante Soares Dutra (Lília Colares, 04/06/2021). 
A escola Municipal Padre Manuel Albuquerque só ofertava o ensino primário até a $4^{\mathrm{a}}$ série, logo, Lília Colares muda-se novamente de instituição educativa, para uma escola que ficava em frente a anterior, chamada Almirante Soares Dutra. Importa destacar, contudo, que não houve apenas mudança de escola, já que com pouco mais de um ano morando com a mãe, foi encaminhada para a casa do pai, que, inclusive, já possuía outra família - esposa e filhos. Ademais, com cerca de seis meses morando com o pai, ele separa-se e vai embora de casa e não leva Lília Colares, de modo que ela permanece morando na casa com a madrasta por cerca de seis anos, até se casar.

Assis e Constantino (2001) nomeiam este fenômeno como "Pingue-Pongue" emocional, ou seja, quando os adolescentes são levados "de um lado para outro", dificultando constituir figuras parentais de referência. Sobre isso, Fialho (2015, p. 265) acrescenta:

Quando afetadas a estabilidade e a segurança dos jovens, ao longo de suas vidas, com o "fenômeno do pingue-pongue emocional", em muitos casos, há uma vivência de condições e limites diferentes que dificultam a compreensão acerca de algumas condutas que podem ser aceitas em determinados ambientes e condenadas em outro. Perde-se, uma orientação mais retilínea e corre-se o risco de, mesmo inconscientemente, fragilizar laços afetivos, relativizar limites impostos e, consequentemente, normas de conduta social.

Observou-se que Lília Colares vivenciou esse Pingue-Pongue emocional e, inclusive, ela infere que suas figuras de referências de pai e de mãe, continuaram a ser seus avós, únicos com os quais nunca perdeu o contato, mesmo tendo sido levada a morar em outros domicílios. Ela teve que conviver em residências com hábitos, crenças religiosas, valores sociais e culturais distintos, todavia, foi a educação fomentada pelos avós que preponderou.

A mudança de escola também dificulta a constituição de laços de amizade, portanto, a escola estadual Almirante Soares Dutra foi lembrada de maneira especial pela biografada porque, diferente das demais, não adotava um ensino pedagógico amparado puramente na corrente tradicional, caracterizado pelo ensino verticalizado, centrado no professor, mnemônico, decorativo, disciplinador e descontextualizado (FIALHO; SOUSA; FREIRE, 2020). Essa escola era conhecida na cidade por sua preocupação com um ensino mais dinâmico e contextualizado, inclusive, realizando muitas festas e articulando a escola com a comunidade. Tempo, considerado por Lília Colares, profícuo para a constituição de novas amizades (Lília Colares, 04/06/2021).

Lília Colares explica que na escola Almirante Soares Dutra, onde ela cursou o final do primeiro grau, era oferecida uma educação mais integradora, na qual os alunos não ficavam apenas na sala de aula ouvindo o que os professores falavam. Havia ainda a preocupação com o desenvolvimento físico e psicossocial dos alunos, o que contribuiu para o seu 
desenvolvimento em relação à interação social com seus pares. Segundo Pereira e Gomes (2018), a disciplina de Educação Física, na década de 1970, foi estabelecida como disciplina obrigatória pela Lei $\mathrm{n}^{\circ} 5.692$ (BRASIL, 1971) - Reforma educacional do ensino de $1^{\circ}$ e $2^{\circ}$ graus.

No ano de 1988, aos 16 anos de idade, Lília Colares foi estudar em uma das maiores escolas de Ensino Secundário de Santarém, Escola Estadual Álvaro Adolfo da Silveira. Lá, ela cursou o segundo grau durante os anos de 1988 a 1990 com habilitação no Magistério, conforme demonstra seu histórico escolar na imagem 2:

Imagem 2 - Histórico Escolar de Lília Colares (Ensino Médio)

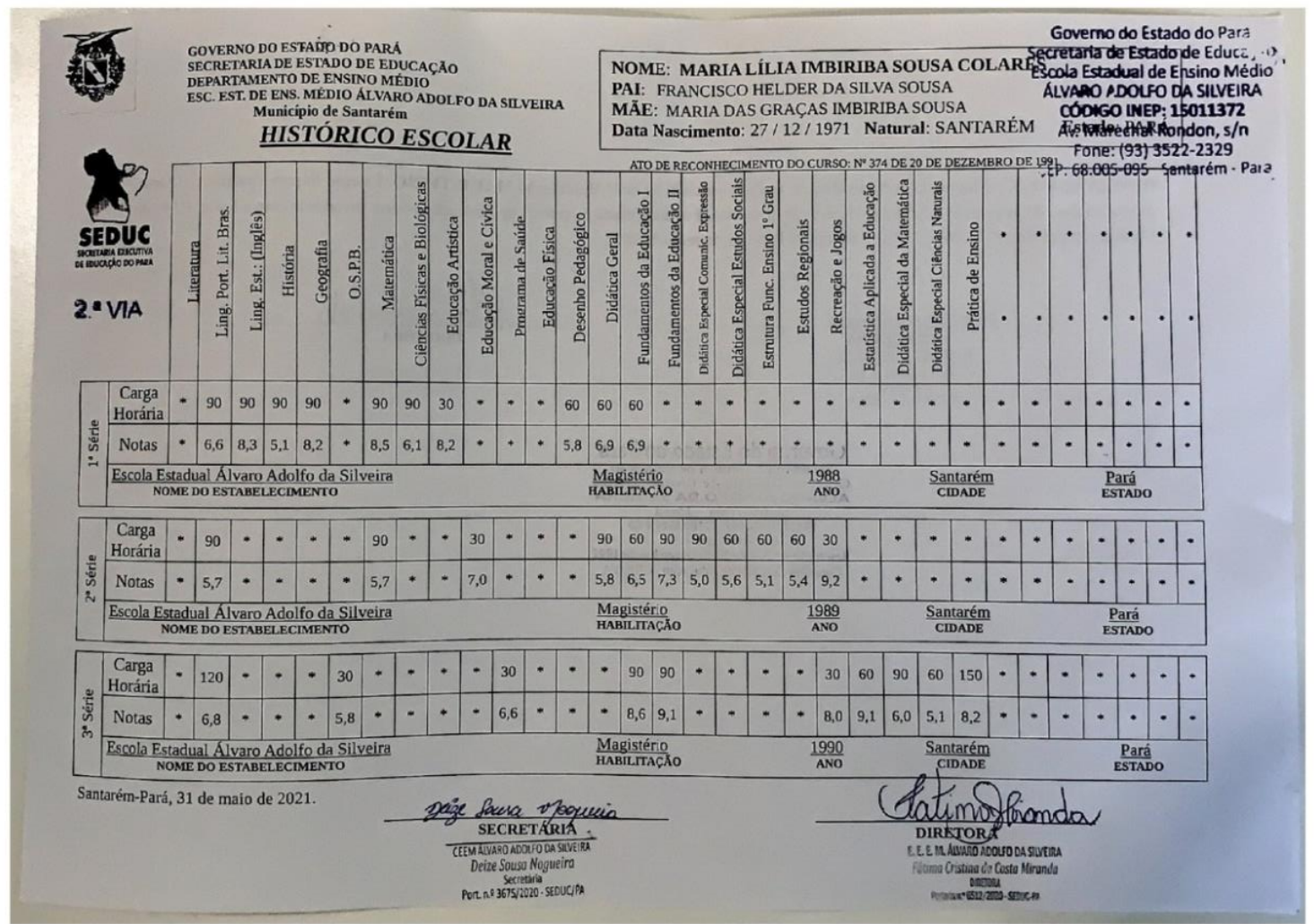

Fonte: Acervo pessoal da biografada

Acerca desse período, ela destaca:

Nessa época que eu comecei a fazer o antigo segundo grau e tinha uma amiga minha que quase todo mundo da família dela era professora [...] e ela frequentava a mesma igreja que eu. Nessa época eu frequentava a igreja presbiteriana e eu fazia o segundo ano do magistério e ela também. O pai dela era o Secretário Municipal de Educação da cidade. A gente morava perto, aí ela me chamou para a gente montar uma escolinha particular, isso concomitante com o meu segundo grau (Lília Colares, 04/06/2021).

Não tendo recursos financeiros, Lília Colares entrou na sociedade com a amiga, com apenas 16 anos de idade, oferecendo seu trabalho como professora e ajudando na administração 
da escola, no entanto, a escola foi fechada pela ausência de recursos financeiros suficientes para se manter, já que sua sócia não conseguiu financiamento e os pais não conseguiam pagar mensalidades: "O nome da escolinha era Rosa de Saron. A gente só conseguiu ficar um ano com essa escola, porque os pais não pagavam as mensalidades dos alunos, então nossa escola faliu praticamente antes de começar" (Lília Colares, 04/06/2021).

No entanto, o pai de sua amiga, por ser professor, que na época era o Secretário de Educação, e ter influência, incentivou e contribuiu para que ambas ingressassem no trabalho na rede de ensino. Lília Colares como professora de educação infantil e a amiga na equipe de coordenação de creches. Lília Colares destaca que "Naquela época as pessoas achavam que se a pessoa não tem formação e tem que começar como professora que seja da Educação Infantil, como se na Educação Infantil você não precisasse ter uma formação para isso [...]" (Lília Colares, 04/06/2021). Em relação à Educação Infantil, foi somente no ano de 2009, com a aprovação da Emenda Constitucional n 59, que a Lei de Diretrizes e Bases da Educação (LDB) (BRASIL, 1996) tornou obrigatória a matrícula de crianças de 4 a 5 anos de idade em préescola. Como até então essa etapa não era obrigatória por lei, tinha-se uma visão equivocada que qualquer pessoa poderia lecionar para crianças pequenas, pois o objetivo maior seria cuidar e não educar.

Depois que concluiu o segundo grau, Lília Colares foi 'promovida', pois foi convidada a lecionar em séries mais adiantadas, para as quais se destinava maior prestígio: “[...] quando eu terminei o segundo grau, digamos assim, eu fui promovida, passei a trabalhar com terceiras e quarta series na escola municipal [...]” (Lília Colares, 04/06/2021). Mesmo já atuando no magistério, Lília Colares ainda não havia decidido se era realmente a docência a profissão que gostaria de exercer por toda a sua vida.

Em 1990, perto dos 19 anos de idade, a educadora prestou vestibular para Pedagogia na Universidade Federal do Pará (UFPA) campus Santarém, iniciando o curso em março de 1991, também entrou em uma faculdade particular para cursar Biologia: "eu resolvi estudar um ano de Biologia que era à noite e estudei um ano Pedagogia que era à tarde e trabalhava pela manhã como professora, isso um ano inteiro, o de 1991, foi muito intenso para mim!" (Lília Colares, 04/06/2021). Como percebeu maior identificação com o curso de Pedagogia, em que já atuava, Lília Colares desistiu de Biologia, permanecendo na formação em Pedagogia.

Sobre a sua formação, elucida que havia uma disciplina chamada "Estudos paraenses", em que o pedagogo poderia trabalhar algumas disciplinas relacionadas à história local, na excepcionalidade, caso não tivesse docente com aquela formação. Então, Lília Colares começou a lecionar as disciplinas de Educação Moral e Cívica (EMC), Organização Social e 
Política Brasileira (OSPB), Estudos paraenses e Educação Artística. Com relação às disciplinas de OSPB e EMC estas se tornaram obrigatórias a partir do Decreto Lei $\mathrm{n}^{\circ} 869$ de 1969 (BRASIL, 1969). Tais disciplinas tinham um caráter de transmissão ideológica do regime autoritário da Ditadura Militar, as quais exaltavam o nacionalismo e o civismo e não levavam à reflexão e à análise do momento político pelo qual o país passava, diferente das disciplinas que a substituíram: História e Geografia. Percebe-se que a biografada, muito jovem e inexperiente, não percebia criticamente o momento político pelo qual o país passava, e, contente por ter a possibilidade de lecionar e estudar, concomitantemente, reproduzia a prática educativa que lhe era ensinada, satisfeita por poder vivenciar a teoria e a prática: "porque ao mesmo tempo em que eu fui me formando, eu já fui também trabalhar, isso traz uma diferenciação na formação" (Lília Colares, 04/06/2021).

No final de 1991, Lília Colares casou-se com Anselmo Colares, também professor. Sobre esse período ela rememora:

[...] dava aula no município, mas não era concursada, era serviço prestado que chamávamos naquela época. [...] trabalhei nas duas redes: municipal e estadual. [...] no terceiro ano de faculdade, eu comecei a dar aula de magistério, na formação de professores, com a disciplina de práticas de ensino para o segundo grau. Fiquei trabalhando nessa escola até eu concluir meu curso de Pedagogia (Lília Colares, 04/06/2021).

Após sua graduação, seu marido fez uma seleção de mestrado e foi aprovado na Faculdade de Educação da Universidade de Campinas (Unicamp). Assim, ela decidiu que iria deixar todos os seus empregos, já que não possuía estabilidade e acompanhar seu esposo em Campinas, em 1996.

Lília Colares, inclusive, seguindo o percurso formativo do marido, cursou algumas disciplinas como ouvinte no mestrado da Unicamp, almejando êxito no processo seletivo. Todavia, como ela relata: "[...] fiquei grávida logo que cheguei lá [...] do nosso primeiro e único filho, o Lucas, e ele nasceu em 1997 (Lília Colares, 04/06/2021). A biografada relembra sua tentativa de ingressar no mestrado: "[...] me inscrevi no mestrado na Unicamp, só que eu não fui aprovada. Eu estava com um barrigão então, como assim você vai fazer o mestrado? Passei na prova escrita, mas fui reprovada na entrevista” (Lília Colares, 04/06/2021). Podese inferir, pelo relato, um sentimento de que, naquele contexto, a gravidez em estado já bem adiantado, tenha produzido um efeito negativo na banca avaliadora quanto ao cumprimento de prazos para a realização do curso.

Lília Colares não desistiu do mestrado e permaneceu com vínculos com a Unicamp “No outro ano continuei estudando como ouvinte, participando do grupo de pesquisa e prestei a 
seleção para o mestrado. Passei e iniciei o mestrado em 1998. Pesquisei gestão. [...] Desde 1996 nunca cortou relações com a Unicamp” (Lília Colares, 04/06/2021). Ao concluir o mestrado, Lília Colares prosseguiu sua formação acadêmica na instituição com o curso de doutorado (2001-2005). Voltando para sua cidade natal, Santarém, em 2003, após cursar as disciplinas, em fase de pesquisa de campo, quando seu marido finalizou seu doutorado.

\section{Atuação Docente e Contribuições Educacionais de Lília Colares}

Ao retornar a Santarém, ainda cursando seu doutorado, Lília Colares recebe o convite para ser coordenadora do curso de Pedagogia da Universidade Luterana do Brasil (ULBRA). Nessa instituição também foi coordenadora de Pesquisa e Pós-Graduação lato $s e n s u^{2}$, onde contribuiu efetivamente para a formação de professores, especialmente com o desenvolvimento de dois projetos que atualmente (2021) ainda são executados, como revela em sua narrativa:

É um trabalho interdisciplinar. Eram feitos projetos com os alunos, projetos que poderiam permear o curso inteiro, poderia depois ser o TCC deles. E tinham culminâncias, no final de cada ano a gente fazia o seminário de trabalhos interdisciplinares, onde os alunos apresentavam os projetos $e$ tinham uma publicação também, havia os anais com os resumos dos alunos. [...] E o outro projeto que continua na ULBRA se chama Colóquios Temáticos em Educação, que eu criei na época que fui professora. Uma vez por mês a gente se organizava e a gente fazia palestras, escolhíamos um tema e cada professor apresentava de acordo com a temática, e no final do ano era lançado um livro com os artigos dos professores e foi quando começaram as produções dos professores do curso de Pedagogia, que hoje já tem muitos livros dos colóquios, mas os três primeiros fui eu que organizei (Lília Colares, 04/06/2021).

Lília Colares foi uma incentivadora da pesquisa e da escrita científica, pois aproveitou sua experiência vivenciada na Unicamp para estimular tanto os alunos como seus pares professores a prosseguir não apenas realizando estudos sobre a realidade paraense, mas também para que prosseguissem suas carreiras acadêmicas em cursos stricto sensu ${ }^{3}$.

Em busca de um emprego estável, Lília Colares passa a acompanhar os concursos para universidades públicas e narra: "Em 2006 eu prestei o concurso para professora para a Universidade Federal de Rondônia, campus de Guajará Mirim” (Lília Colares, 04/06/2021). Ela logrou êxito na seleção e sua nomeação no Diário Oficial da União saiu no dia 1 de março de 2006.

\footnotetext{
2 Pós-graduação latu sensu compreendem os programas de especialização e/ou cursos denominados Master Business Administration - MBA.

${ }^{3}$ Pós-graduação em nível de mestrado e doutorado.
} 
Lília Colares foi nomeada para assumir o Cargo Efetivo de Professora do Magistério Superior, em Regime de Dedicação Exclusiva (40h) na Área de Pedagogia no campo de conhecimento Didática e Prática de Ensino. Com efeito, “[...] como tinha poucos professores no campus eu acabei trabalhando com política, com gestão e acabei nunca saindo da área que eu gosto que é política e gestão da educação” (Lília Colares, 04/06/2021). Ela considerou positivo o fato de poder ir para a área com a qual mais se identificava sem qualquer problema, ademais, dessa vez, foi seu esposo quem pediu transferência para acompanhá-la em Rondônia.

Em 2008, Lília Colares foi chamada para compor o quadro do Programa de PósGraduação, no curso de Mestrado em Educação da Universidade Federal de Rondônia (Unir), na cidade de Porto Velho, onde colaborou desde a criação do projeto. No entanto, o maior desejo dela era retornar para a sua cidade de origem, Santarém, e contribuir com a formação de professores do local. Sonho esse que se tornou possível porque em 2009, foi criada a Ufopa, ocasião em que o primeiro reitor pró tempore produziu e fez circular uma mensagem (vídeo) na qual incentivava professores mestres e doutores a compor o quadro docente da instituição e fazia uma espécie de apelo, aos santarenos ou nascidos na região, para que ajudassem a construir a primeira universidade pública federal do interior da Amazônia. Esse chamamento foi importante na tramitação do processo de redistribuição da Unir para a Ufopa, que se consumou-se em março de 2010.

Retornando a Santarém, utilizando a experiência em Programa de Pós-Graduação stricto sensu que já possuía e por meio dos contatos profícuos que haviam cultivado na Unicamp, Lília Colares e Anselmo Colares logo cuidaram de lutar para a implantação de um doutorado na região:

A gente fez um projeto com a Unicamp, porque a gente queria formar professores do Doutorado em Educação, para que a gente pudesse abrir o nosso próprio programa de Pós-Graduação. Fizemos o Doutorado Interinstitucional - Dinter que foi de 2012 a 2016. No começo desse Dinter, o Anselmo (esposo) era o coordenador, ficou sendo até 2013. Em 2014 eu passei a ser coordenadora do Dinter porque o Anselmo foi eleito o vice-reitor da Ufopa, e eu assumi a coordenação do Doutorado Interinstitucional que foi até o final de 2016. Depois disso, aqui na Ufopa a gente conseguiu em 2013 aprovar o nosso Programa de Pós-Graduação, foi instituída a comissão [...] a gente fez o projeto e conseguiu o Mestrado em Educação em 2013, a nossa primeira turma foi em 2014 e a gente continua até hoje. Esse é o nosso oitavo ano do programa e a gente já formou mais de 130 mestres na área da educação (Lília Colares, 04/06/2021).

Ainda que Lília Colares considere que sua maior contribuição para o cenário educacional de Santarém tenha sido sua atuação na docência desde a fundação da Ufopa e sua atuação na constituição do Programa de Pós-Graduação (PPGE) da Ufopa, ela destaca a colaboração exercida no Programa Nacional Escola de Gestores da Educação Básica Pública, 
uma política pública do Ministério da Educação (MEC) que tem como objetivo contribuir com a qualificação dos gestores escolares na perspectiva de uma gestão democrática: "Enquanto profissional, além do Dinter implementei na Ufopa, com ajuda de outros professores, o Programa Escola de Gestores, que era um programa para formar diretores na perspectiva da gestão democrática" (Lília Colares, 04/06/2021). Ela explica que o referido programa formou aproximadamente dois mil gestores:

[...] tenho muito orgulho de ter coordenado esse trabalho, e que tanta gente teve condições de ler textos para melhorar o seu trabalho na perspectiva da gestão democrática. A gente sabe que a gestão democrática existe na forma da lei desde 1988, mas, se você for fazer um estudo, são poucas as escolas que trabalham nessa perspectiva. [...]. A gente entende que a gestão ela não é só trabalho do diretor da escola, mas da equipe da escola, por isso a gente sempre trabalhou nessa perspectiva de formar a equipe gestora como um todo (Lília Colares, 04/06/2021).

No relato, é possível observar que sua atuação no campo da gestão educacional e na formação de professores ultrapassa o âmbito do ensino superior e envolve também a educação básica. Inclusive, para ampliar os conhecimentos no campo da gestão escolar, Lília Colares ingressou no curso de Pós-doutorado (2012-2013) na Unicamp, para desenvolver pesquisa sobre essa temática, especificamente sobre as reverberações na práxis dos gestores que fizeram o curso da Escola de Gestores da Ufopa.

Lília Colares entende que sua trajetória formativa pode ser considera uma exceção, isso porque para as outras mulheres professoras de Santarém nunca foi fácil conseguir um doutorado pela ausência desse nível de formação na cidade. Buscando contribuir para reverter essa problemática, teve papel ativo no estabelecimento de cooperação com a Unicamp para a oferta do doutorado interinstitucional e a criação do Doutorado em Rede, no qual todas as nove universidades públicas da região Norte participam. Ela foi designada pela reitoria da Ufopa para representar a instituição na reunião em que se deu o início da formatação do curso, na Universidade Federal do Amazonas, em 2016. O curso foi aprovado pela Coordenação de Aperfeiçoamento de Pessoal de Nível Superior em 2019, com a primeira turma iniciando suas atividades em quatro polos: Belém, Manaus, Palmas e Santarém.

Com toda a minha persistência e meu envolvimento com a Unicamp, consegui superar algumas barreiras e pude participar de algumas atividades com eles, por exemplo Procad/Unicamp/Unir, participação ativa em grupos de pesquisa, doutorado interinstitucional etc. $O$ que eи е теи marido sempre pensamos [...] esse compromisso eu preciso voltar, eu preciso trabalhar, preciso devolver essa contribuição para universidade pública e para a região Norte. (Lília Colares, 04/06/2021). 
Para Lília Colares, conseguir fomentar em Santarém um curso de doutorado é uma conquista para o povo do oeste do Pará, que sempre teve muita dificuldade para alcançar esse nível formativo. Inclusive, explica quais são os sacrifícios exigidos:

\begin{abstract}
Hoje quando a gente vê os nossos mestrandos fazendo a Pós-Graduação aqui em Santarém sem ter que se sacrificar, porque é muito difícil (sente alegria). Eu não falo de preconceito porque a gente nunca sentiu assim um preconceito por ser do Norte. Não se trata disso, se trata de questão financeira mesmo, de ficar longe da sua família, de você não ter como se manter, porque por mais que você tenha uma bolsa de mestrado que é um pouco mais de um saláriomínimo não tem como pagar aluguel e em Campinas tudo é caro (Lília Colares, 04/06/2021).
\end{abstract}

A biografada, ao expor as dificuldades de um aluno para realizar um cursar stricto sensu, sensibilizada com as limitações impostas, desenvolveu o senso de compromisso com a educação de seu povo. Ela relata, todavia, que já houve o desenvolvimento regional, apontado como inegável, especialmente depois que foi institucionalizada a Universidade Federal com o campus da Ufopa.

Ante toda a sua trajetória formativa, Lília Colares reflete sobre a sua carreira:

[...] vésperas de fazer o concurso para professora titular me sinto assim mais preparada, e vejo muitos frutos, tenho mais de 20 egressos do curso de mestrado que ajudei nessa formação humana e profissional. E agora mais recente eu fui convidada para integrar um programa de doutorado. Infelizmente, para a gente do Norte, não é fácil conseguir essa formação. A gente só tinha um mestrado, e não tinha nenhum doutorado na área da Educação em Santarém (Lília Colares, 04/06/2021).

A sua carreira, dedicada ao ensino, pesquisa, extensão e gestão foi recentemente reconhecida pelo Conselho Nacional de Desenvolvimento Científico e Tecnológico (CNPq), que lhe concedeu bolsa produtividade em 2018.

Ainda sobre o compromisso que assumiu com a educação, Lília Colares deixa explícito que pode contribuir ainda mais com o cenário educativo, não apenas incentivando outros alunos a serem bons profissionais, mas também na difusão do conhecimento produzido. Por fim, sobre a sua formação, fala sobre a contribuição no Fórum de editores:

O Fórum de editores Norte e Nordeste é importante na minha formação e trajetória profissional, comecei a ser editora da revista Exitus em 2010, estou comemorando dez anos de editoria da revista, isso foi algo muito forte na minha formação dentro da universidade. [...] a gente teve a condição e a possibilidade de se formar editor em conjunto com o fórum Norte e Nordeste, hoje somos um grupo, somos muito coesos e a gente se preocupa com a produção e disseminação da produção do conhecimento. A gente não se contentou apenas em formar alunos, queremos, além de formar, difundir o que a gente produz. [...] (Lília Colares, 04/06/2021). 
Em sua narrativa, Lília Colares destaca sobre a sua atuação como editora de periódico científico e a importância dessa atividade para a disseminação do conhecimento. E acrescenta a relevância do saber social para a sua formação profissional, da aprendizagem decorrente da interação com seus pares, afinal, “[...] um professor nunca define sozinho e em si mesmo o seu próprio saber profissional” (TARDIF, 2014, p. 12), pois ele é constituído por toda a vida experienciada em sociedade.

\section{Considerações Finais}

A biografia da trajetória formativa da educadora Lília Colares compreendeu aspectos familiares, formativos e profissionais, isso porque “[...] o saber dos professores é plural e também temporal, [...] é adquirido no contexto de uma história de vida e de uma carreira profissional" (TARDIF, 2014, p. 19-20). A formação na e para a docência é contínua e dinâmica, envolvendo saberes que vão sendo adquiridos e ressignificados por experiências sociais ao logo da vida.

Problematizou-se como se deu a formação educativa da professora Lília Colares para que ela pudesse atuar profissionalmente contribuindo para a expansão do ensino superior em nível de pós-graduação stricto sensu na cidade de Santarém no estado do Pará. Para desvelar essa questão buscou-se compreender a trajetória educativa de Lília Colares, com ênfase nas experiências formativas e profissionais que lhe possibilitaram galgar nível pós-doutoral e contribuir efetivamente com o contexto educacional de Santarém.

Tomando como objeto de estudo as narrativas em história oral de Lília Colares, constatou-se que ela foi educada na infância pelos avós, pessoas de poucas posses e escolarização, mas que valorizavam a educação, por perceberem nos estudos a única oportunidade de a neta conseguir uma boa profissão. Todavia, a estada na casa dos avós foi interrompida pela decisão da mãe de levá-la para morar consigo, depois da primeira década de vida da filha. Mudança esta que durou cerca de um ano e meio, pois, em seguida, foi direcionada para a casa do pai, que já possuía outra família. A permanência com o pai, com efeito, foi ainda menor, pois ele separou-se da esposa, saiu de casa, deixando-a sob os cuidados da madrasta.

Esse pingue-pongue emocional dificultou a constituição não apenas da figura de referência materna e paterna, mas no desenvolvimento de amizades duradouras na adolescência. Isso porque Lília Colares também se mudou bastante de escola, iniciando seus estudos numa escola domiciliar denominada Escolinha da Professora Léo, em seguida, indo cursar as três primeiras séries do primário na Escola Municipal Rotary, a quarta série primária na Escola Municipal Padre Manuel Albuquerque, a quinta série na Escola Julia Gonçalves Passarinho e 
as séries finais do primário da Escola Estadual Almirante Soares Dutra. Todas essas escolas trabalhavam numa perspectiva tradicional de educação, com exceção da última que investia na interação escola e sociedade e fomentou, em meio a festas e comemorações, condições para que Lília Colares estabelecesse laços mais sólidos de amizade.

O ensino secundário, com formação no Magistério, deu-se concomitante as suas primeiras experiências profissionais, a princípio com a tentativa de montar sua própria escola e, em seguida, em contratos públicos arranjados por indicação política. Todavia, foi após iniciar o curso de Pedagogia na UFPA que Lília Colares foi desenvolvendo uma identidade com a docência e o compromisso com a educação do povo paraense.

Foi o casamento com Anselmo Colares e, mais especificamente, sua mudança para Campinas para acompanhar o marido no seu curso de mestrado na Unicamp, que oportunizou seu ingresso como ouvinte e, posteriormente, como aluna dessa instituição. Mesmo sendo mãe recentemente, em cidade ainda pouco conhecida, Lília Colares conseguiu não apenas concluir seu mestrado, doutorado e pós-doutorado, mas estabelecer laços sólidos acadêmicos que reverberaram na execução de projetos em prol da formação profissional dos professores santarenos.

Lília Colares atuou no Programa Nacional Escola de Gestores da Educação Básica Pública, protagonizando formação em gestão democrática para inúmeros diretores e coordenadores escolares, ademais, fomentou projetos de pesquisa e escrita científica junto a alunos e professores da ULBRA. Também atuou na implementação de curso mestrado e doutorado, na coordenação de programa de pós-graduação e na editoria de revista científica.

Apesar das dificuldades encontradas em seu percurso formativo, com a mudança de escolas e até de cidade para conseguir prosseguir com os estudos, Lília Colares destacou-se como mulher e educadora do Norte, uma referência na educação da cidade de Santarém como professora do Ensino Superior, no âmbito da Pós-Graduação em Educação e como editora de periódico.

Biografar a educadora Lília Colares não permite esgotar as nuances que envolvem a História da Educação no Pará, mas possibilita refletir sobre parte dessa tessitura, bem como compreender algumas especificidades da Região Norte. Assim, observou-se que, até o fim do século XX, na região em questão, havia uma escassez de programas de pós-graduação impossibilitando que graduados dessem continuidade a sua formação acadêmica. Esse fato asseverava desigualdades regionais e estabelecia uma dependência educacional de outras regiões que perdurou por dezenas de anos. Dessa maneira, sugere-se outros estudos que possam 
pesquisar o desenvolvimento local gerado pela expansão universitária de Santarém, já que os estudos biográficos possuem a limitação de serem passíveis de generalizações.

\section{REFERÊNCIAS}

ALVES, F. C.; FIALHO, L. M. F. Currículo na educação infantil: O que pensam os professores?. Práxis educacional, v. 15, p. 251-272, 2019. Disponível em: http://periodicos2.uesb.br/index.php/praxis/index. Acessado em 25 jul. 2021.

ASSIS, S. G.; CONSTANTINO, P. Filhas do mundo: infração juvenil feminina no Rio de Janeiro. Rio de Janeiro: Editora FIOCRUZ. 2001.

BOGDAN, R.C.; BIKLEN, S.K. Investigação qualitativa em educação: uma introdução à teorias e aos métodos. Tradução Maria Joao Alvarez, Sara Bahia dos Santos e Telmo Mourinho Baptista. Portugal: Porto Editora, 1994.

BOSI, E. Memória e sociedade: lembranças de velhos. 3. ed. São Paulo: Companhia das Letras, 1994.

BURKE, P. O que é História Cultural?. Tradução de Sérgio Goes de Paula. Rio de Janeiro: Jorge Zahar, 2005.

BURKE, P. (Org.). A escrita da história. Tradução de Magda Lopes. São Paulo: UNESP, 2011.

BRASIL. Presidência da República. Decreto-lei no 869, de 12 de setembro de 1969. Disponível em: http://www.planalto.gov.br/ccivil_03/decreto-lei/19651988/Del0869.htm. Acesso em: 26 jul. 2021.

BRASIL. Leis de Diretrizes e Bases da Educação Nacional. Lei no 9.394 de 1996. Disponível em: http://www.planalto.gov.br/ccivil_03/leis/19394.htm. Acesso em: 27 jul. 2021.

BRASIL. Lei $\mathrm{n}^{\circ}$ 5.692, de 11 de agosto de 1971. Fixa Diretrizes e Bases para o Ensino de $1^{\circ} \mathrm{e}$ $2^{\circ}$ Graus, e dá outras providências. Diário Oficial [da] República Federativa do Brasil, Poder Executivo, Brasília, DF, 12 ago. 1971.

CARINO, J. A. A biografia e sua instrumentalidade educativa. Educação e Sociedade, Campinas, v. 20, n. 67, p.153-182, 1999. Disponível em: https://www.scielo.br/j/es/a/pfcpbdYWBNLMVktGRhKKNYM/abstract/?lang=pt Acesso em: 11 ago. 2021.

CHARTIER, Roger. A história cultural entre práticas e representações. Trad. de Maria Manuela Galhardo. Lisboa: Difusão Editora, 1988.

COLARES, M. L. I. S. Entrevista concedida a Francisca Mayane Benvindo dos Santos por Maria Lília Imbiriba Sousa Colares. Google Meet, 4 de junho de 2021. Duração: 1h15 $\min$.

DOSSE, F. O desafio biográfico: escrever uma vida. 2. ed. São Paulo: Universidade de São Paulo, 2015. 
ESQUISANI, R. S. S. Entre percursos, fontes e sujeitos: pesquisa em educação e uso da história oral. Educação e Pesquisa, v.38, n. 1, p. 217-228, mar. 2012. Disponível em https://www.scielo.br/j/ep/a/dQtstrhQB3GQjC4Kx7smv4y/?lang=pt Acesso em 11 ago. 2021.

FIALHO, L. M. F. A vida de jovens infratores privados de liberdade. Fortaleza: Edições UFC, 2015.

FIALHO, L. M. F; CARVALHO, S. O. C. História e memória do percurso educativo de Célia Goiana. Série Estudos, v. 22, p. 137-157, 2017. Disponível em: http://www.serieestudos.ucdb.br/index.php/serie-estudos /article/view/992. Acesso em 2 de julho de 2021.

FIALHO, L. M. F; SANTOS, M. B; SALES, J. A. M. Pesquisas biográficas na história da educação. Cad. Pesq., v.26, n.3, jul./set, 2019. Disponível em http://www.periodicoseletronicos.ufma.br/index.php/cadernosdepesquisa/article/view/12743/0 Acesso em: 11 ago.2021.

FIALHO, L. M. F.; FREIRE, V. C. C. Educação formativa de uma líder política cearense: Maria Luiza Fontenele (1950-1965). Cadernos de História da Educação, v. 17, p. 343, 2018. Disponível em: http://www.seer.ufu.br/index.php/che/article/view/43290. Acesso em: 29 abr. 2021.

FIALHO, L. M. F.; LIMA, A. M. S.; QUEIROZ, Z. F. Biografia de Aída Balaio: prestígio social de uma educadora negra. Educação Unisinos, v. 23, p. 48-67, 2019. Disponível em: http://revistas.unisinos.br/index.php/educacao/article/view/edu.2019.231.04. Acesso em: 28 abr. 2021.

FIALHO, L. M. F.; QUEIROZ, Z. F. Maria Neli Sobreira: história e memória da educação em Juazeiro do Norte. Educar em Revista, v. 34, p. 67-84, 2018. Disponível em: http://www.scielo.br/scielo.php?script=sci_abstract\&amp;pid=S010440602018000400067\&a mp;lng=pt\&amp;nrm=iso. Acesso em: 28 abr. 2021.

FIALHO, L. M. F.; SA, E. C. V. Educadora Henriqueta Galeno: a biografia de uma literata e feminista (1887- 1964). História da Educação, v. 22, p. 169-188, 2018. Disponível em: https://seer.ufrgs.br/asphe/article/view/75182 Acesso em: 29 abr. 2021.

FIALHO, L. M. F.; SANTOS, H. F.; FREIRE, V. C. C. Biografia da Professora Raquel Dias Araújo: um olhar sobre a docência universitária e a militância política. History of Education in Latin America - HistELA, v. 3, p. 1-14, 2020. Disponível em: https://periodicos.ufrn.br/histela/article/view/20562/12765. Acesso em: 29 abr. 2021.

FIALHO, L. M. F.; SOUSA, F. G. A.; NASCIMENTO, L. B. S. Biografia da educadora Josete Sales: reflexos da formação de professoras no Ceará. Roteiro, v. 45, 2020. Disponível em: https://portalperiodicos.unoesc.edu.br/roteiro/article/view/23790 Acesso em: 29 abr. 2021.

FIALHO, L. M. F.; SOUSA, N. M. C.; DIAZ, J. M. H. Rosa Maria Barros Ribeiro: memórias da trajetória formativa para docência. Revista Cocar, v. 8, p. 371-387, 2020. Disponível em: https://paginas.uepa.br/seer/index.php/cocar/article/view/3083 Acesso em: 29 abr. 2021.

FIALHO, L. M. F.; SOUSA, F. G. A.; FREIRE, V. C. C. Pesquisas em História da Educação publicadas por periódicos do Norte e Nordeste do Brasil. Práxis Educacional, v. 16, p. 382403, 2020. Disponível em: https://periodicos2.uesb.br/index.php/praxis/article/view/6904 
FIALHO, L.M. F.; HERNÁNDEZ DÍAZ, J. M. Maria Zelma de Araújo Madeira: memórias de formação e resistências da docente universitária negra. Revista Diálogo Educacional, v. 20, p. 775-796, 2020. Disponível em:

https://periodicos.pucpr.br/index.php/dialogoeducacional/article/view/26441 Acesso em: 28 abr. 2021.

FIALHO, L. M. F.; SOUSA, F. G. A. de. Irmã Elisabeth Silveira e a educação feminina no Colégio da Imaculada Conceição, Fortaleza-CE. Revista Diálogo Educacional, v. 21, p. 191316, 2021. Disponível em:

https://periodicos.pucpr.br/index.php/dialogoeducacional/article/view/27388. Acesso em: 28 abr. 2021.

FREITAS, M. C.; BICCAS, M. S. História social da educação no Brasil (1926-1996). São Paulo: Cortez, 2009.

GODINHO, T. Mulheres brasileiras: reinventando a vida, a história, a cultura. In:

ASSIS, M. E. A; SANTOS, T. V. (Org.) Memória feminina: mulheres na história, história de mulheres. -Recife: Fundação Joaquim Nabuco. Editora Massangana, 2016.

INSTITUTO BRASILEIRO DE GEOGRAFIA E ESTATÍSTICA - IBGE. Cidades. 2010. Disponível em https://cidades.ibge.gov.br/brasil/pa/santarem/panorama

LE GOFF, J. História e Memória. Campinas, SP: Editora Unicamp, 1990.

LEVI, G. Sobre a Micro-História. In: BURKE, P. (Org.). A escrita da História: novas perspectivas. São Paulo: Unesp, 1992. p. 133-162.

LOPES, T. M. R.; SOUSA, F. G. A.; FIALHO, L. M. F. Maria Zuíla e Silva Morais: Pioneirismo e protagonismo na fundação da Apae de Juazeiro. Revista Entreideias: Educação, Cultura e Sociedade, v. 9, p. 89-108, 2020. Disponível em: https://periodicos.ufba.br/index.php/entreideias/article/view/35197 Acesso em: 29 abr. 2021.

LORIGA, S. O pequeno x: da biografia à história. Belo Horizonte: Autêntica, 2011.

LOZANO, J. E. A. Prática e estilos de pesquisa na história oral contemporânea. In: FERREIRA, Marieta de Moraes; AMADO, Janaína. Usos e abusos da história oral. $8^{\text {a }}$. ed. Rio de Janeiro: FGV, 2006. p.15-25.

MAINETTI, A. C; WANDERBROOCKE, A. C. N. de S. Avós que assumem a criação de netos. Pensando fam., Porto Alegre, v. 17, n. 1, p. 87-98, jul. 2013. Disponível em: http://pepsic.bvsalud.org/scielo.php?script=sci_arttext\&pid=S1679494X2013000100009\&lng=pt\&nrm=iso. Acesso em: 27 jul. 2021.

MEIHY, J. C. S. B.; HOLANDA, F. História oral: como fazer como pensar. São Paulo: Contexto, 2007.

MINAYO, M. C. S. Pesquisa social: teoria, método e criatividade. 18. ed. Petrópolis: Vozes, 2001.

MENDES, M. C. F.; COSTA, M. A. A.; BRANDENBURG, C.; FIALHO, L. M. F. Iolanda dos Santos Mendonça: a participação das mulheres em movimentos indígenas (1970-2000). 
Cambios y Permanencias, v. 11, p. 828-853, 2020. Disponível em: https://revistas.uis.edu.co/index.php/revistacyp/article/view/11094 Acesso em: 29 abr. 2021.

MENDES, M. C. F.; FIALHO, L. M. F.; MACHADO, C. J. S. Argentina Pereira Gomes: disseminação de -inovações- didáticas na educação primária na década de 1930. Revista Diálogo Educacional, v. 19, p. 527-550, 2019. Disponível em: https://periodicos.pucpr.br/index.php/dialogoeducacional/article/viewFile/24959/23519. Acesso em: 28 abr. 2021.

PEREIRA, A. S. M.; GOMES, D. P. Educación Física en Brasil: recorrido histórico educativo de 1851 a 2017. Lecturas: Educación Física y Deportes, v. 22, n. 238, p. 94-101, 25 mar. 2018. Disponível em: https://www.efdeportes.com/efdeportes/index.php/EFDeportes/article/view/93.Acesso em: 26 jul. 2021.

RODRIGUES, R. M. Biografia e Gênero. In: FIALHO, L. M. F, VASCONCELOS, J. G, SANTANA, J. R. (Orgs.). Biografia de Mulheres. Fortaleza: EdUECE, 2015.

TARDIF, Maurice. Saberes docentes e formação profissional. Petrópolis - RJ: Vozes, 2014.

THOMPSON, P. A voz do passado. Tradução de Lólio Lourenço de Oliveira. Rio de Janeiro: Paz e Terra, 1992.

VILAS-BOAS, Sergio. Biografismo: reflexões sobre as escritas da vida. 2. ed. São Paulo: Unesp, 2014.

\section{SOBRE AS AUTORAS:}

\section{Lia Machado Fiuza Fialho}

Doutora em Educação Brasileira (UFC). Professora do Centro de Educação, do Programa de Pós-Graduação em Educação e do Mestrado Profissional em Planejamento e Políticas Públicas da Universidade Estadual do Ceará (UECE). Líder do Grupo de Pesquisa Práticas Educativas Memórias e Oralidades (PEMO/UECE). Editora da revista Educação \& Formação. Pesquisadora produtividade CNPq. E-mail: lia.fialho@uece.br

(iD https://orcid.org/0000-0003-0393-9892

\section{Scarlett O'hara Costa Carvalho}

Doutoranda em Educação (UECE). Bolsista Capes/Funcap pelo Programa de Pós-Graduação em Educação da Universidade Estadual do Ceará (UECE). Integrante do Grupo de Pesquisa Práticas Educativas, Memórias e Oralidade (PEMO/UECE). E-mail:

scarlettoharacc@gmail.com

iD https://orcid.org/0000-0002-0381-0063

\section{Francisca Mayane Benvindo dos Santos}

Mestra pelo Programa de Pós-Graduação em Educação da Universidade Estadual do Ceará (UECE). Integrante do Grupo de Pesquisa Práticas Educativas, Memórias e Oralidade (PEMO/UECE). E-mail: mayanebenvindo@gmail.com

(iD https://orcid.org/0000-0002-4923-3759 


\section{Arliene Stephanie Menezes Pereira}

Docente do Instituto Federal de Educação, Ciência e Tecnologia do Ceará (IFCE). Doutoranda pelo Programa de Pós-Graduação em Educação da Universidade Estadual do Ceará (UECE). Integrante do Grupo de Pesquisas Práticas Educativas, Memórias e Oralidades (PEMO/UECE). E-mail: stephanie_ce@hotmail.com

(iD https://orcid.org/0000-0002-3042-538X

Recebido em: 25 de agosto de 2021 Aprovado em: 01 de setembro de 2021 Publicado em: 13 de setembro de 2021 